\title{
UNIFORM BOUNDEDNESS OF CONDITIONAL EXPECTATION OPERATORS ON A BANACH FUNCTION SPACE
}

\author{
MASATO KIKUCHI
}

Abstract. Let $X$ be a Banach function space over a nonatomic probability space. The quasiBanach space weak $-X$ is defined in a natural way. We give some necessary and sufficient conditions on $X$ for all the conditional expectation operators to be uniformly bounded operators from $X$ into weak- $X$.

Mathematics subject classification (2010): 46E30, 47B38, 60G42.

Keywords and phrases: Conditional expectation operator, Banach function space, weak type inequality, martingale inequality.

\section{REFERENCES}

[1] C. Bennett And R. Sharpley, Interpolation of operators, Academic Press, Boston, 1988.

[2] S. Bloom And R. KeRman, Weighted $L_{\Phi}$ integral inequalities for operators of Hardy type, Studia Math. 110, 1 (1994), 35-52.

[3] K. M. Chong AND M. N. RICE, Equimeasurable rearrangements of functions, Queen's Papers in Pure and Appl. Math. 28, Queen's Univ., Kingston, Ontario, 1971.

[4] C. Dellacherie And P. A. Meyer, Probabilités et potentiel, Chapitres V à VIII, Hermann, Paris, 1980.

[5] L. Grafakos And N. Kalton, Some remarks on multilinear maps and interpolation, Math. Ann. 319, 1 (2001), 151-180.

[6] M. KIKUCHI, Boundedness and convergence of martingales in rearrangement-invariant function spaces, Arch. Math. (Basel) 75, 4 (2000), 312-320.

[7] M. KIKUCHI, On weighted weak type maximal inequalities for martingales, Math. Inequal. Appl. 6, 1 (2003), 163-175.

[8] M. KIKUCHI, Characterization of Banach function spaces that preserve the Burkholder squarefunction inequality, Illinois J. Math. 47, 3 (2003), 867-882.

[9] M. KIKUCHI, On some mean oscillation inequalities for martingales, Publ. Mat. 50, 1 (2006), 167189.

[10] S. G. KreǏn, Yu. I. Petunin, And E. M. Semenov, Interpolation of linear operators, Translations of Mathematical Monographs 54, American Mathematical Society, Providence, 1982.

[11] L. Maligranda, Orlicz spaces and interpolation, Seminários de Matemática 5, Universidade Estadual de Campinas, Departamento de Matemática, Campinas, 1989.

[12] L. MaligRanda, Józef Marcinkiewicz (1910-1940) - on the centenary of his birth, Banach Center Publ. 95 (2011), 133-234.

[13] L. C. G. Rogers And D. Williams, Diffusions, Markov processes, and martingales, Volume 1, Foundations (2nd. ed.), Wiley \& Sons, Ltd., Chichester, 1994.

[14] E. M. SEMEnov, Imbedding theorems for Banach spaces of measurable functions, Sov. Math., Dok1. 5 (1964), 831-834.

[15] E. STEIN AND G. Weiss, Introduction to Fourier analysis on Euclidean spaces, Princeton University Press, Princeton, 1971. 